\title{
Anatomical Variations in Branching Pattern and Dimensions of Coronary Arteries: A Cadaveric Study from South India
}

\author{
Dr M. Venkateshwer Reddy ${ }^{1}$, Dr Bheemesh Pusala ${ }^{2}$ \\ ${ }^{1}$ (Associate Professor, Department Of Anatomy, SVS Medical College, Mahaboobnagar, Telangana, India). \\ ${ }^{2}$ (Tutor, Department Of Anatomy, ESIC Medical College, Sanathnagar, Hyderabad Telangana, India).
}

\begin{abstract}
:
Introduction: Clinicians and anatomists have been examining coronary artery variations for a long time. However, there is still no consensus on the normality or abnormality of coronary arteries. The present survey was therefore conducted to find out the variations in branching pattern and dimensions of Left coronary artery (LCA) and Right coronary artery (RCA)

Material and methods: The present study was planned and conducted during 2009 to 2015 at Department of Anatomy, SVS medical college and teaching hospital, Mahabubnagar, telangana state. The hearts of 110 adult south Indian cadavers fixed with $10 \%$ formaldehyde were used. .

Instruments Used: Scalpel,Forceps,Scissors, Vernier caliper,Scale and Thread

Methods: Dissection method: To secure the heart specimen.

KOH Method : To separate the muscle mass.

Fevicryl crimson red colour: To highlight the arterial system.

- Results \& Conclusions:

- Dimensions of coronary artery

Diameter: Right coronary artery 2 to $5 \mathrm{~mm}$ only and Left coronary artery from 2 to $6 \mathrm{~mm}$ only.

Length of coronary arteries ranges

RCA: 100 to $130 \mathrm{~mm}$, PDA (Posterior Descending Artery): 30 to $50 \mathrm{MM}$,

LCMT(Left coronary Artery main trunk ): 15 to 25MM, LAD(Left anterior Descending Artery): 120 to $145 M$ M, LC(Left circumflex Artery): 60 to 80MM

- Branching pattern

Right coronary artery

Right aortic sinus continues as a RCA in $70 \%$ hearts, Right aortic sinus bifurcated as RCA \& Conus artery in $30 \%$ hearts . single PDA arises from RCA in 80\% hearts 2 or 3 PDA arises from RCA in $20 \%$ hearts .

Left coronary artery LCA bifurcated $86 \%$ trifurcated $14 \%$ length of main trunk 7.38 in normal, bifurcated $7.46 \mathrm{~mm} \&$ trifurcated $6.86 \mathrm{~mm}$.Knowledge of individual and racial variations in coronary arteries is essential for the diagnosis and treatment of coronary artery disease patients.
\end{abstract}

Keywords: Left circumflex Artery $(L C)$, Left coronary artery (LCA) , Posterior Descending Artery (PDA) , Right coronary artery (RCA), Variations,

\section{Introduction}

Cardia is from the Greek word Kardia, meaning heart. It is the heart that provides the motive force acting as a pump to move blood through the circulatory system. Heart receives its blood supply from the coronary vessels. It may seem like the heart has easy access to blood, however the blood passing through the chambers of heart does not actually supply it, instead special blood vessels, called coronary arteries deliver blood into heart muscle itself.

The word coronary is derived from the Latin word co-ro-ne, Greek ko ro ne, means anything hooked or curved and coronary means 'encircling in a manner of crown'. [1]

Arterial supply to heart is achieved by two arteries, which are the only branches from ascending aorta. These arteries branch in such a manner that they occupy atrioventricular and interventricular groove in the shape of a crown. Hence they are called the coronary arteries. ${ }^{[2]}$

Coronary arteries are the largest vasa vasorum of the heart, the heart develops from the fusion of two primitive endothelial tubes, which represent the ventral aorta. The right coronary artery arises from the right coronary sinus (anterior aortic sinus) of the ascending aorta and the left coronary artery arises from the left posterior aortic sinus of the ascending aorta. ${ }^{[3]}$ Ostia of the coronary arteries are located in the center of the corresponding aortic sinuses. Malformations of the position of the ostia and origin of coronary arteries lead to high risk of sudden death. ${ }^{[4]}$ 
Vascular anomalies pose a great challenge to anatomists and Cardio-Thoracic surgeons. Knowledge of normal coronary anatomy and its variations or anomalies is essential in heart surgeries. Failure in detection of these anomalies leads to complications. ${ }^{[5]}$

Holsted, a pioneer American surgeon has said that the best way to avoid injury to blood vessels is to know all possible variations in course, distribution and branches. Any surgical trauma sustained by blood vessels is irreparable leading to the necrosis of the part involved.

The coronary arteries, studied for many years to determine the pathophysiology of coronary artery disease, have been under intense scrutiny by those attempting to revascularize areas of ischemic myocardium using grafts to bypass arteries that have become obstructed by atheroma. ${ }^{[6]}$

Knowledge of normal and variant anatomy and anomalies of coronary circulation is an increasingly vital component in the management of congenital and acquired heart diseases. ${ }^{[7]}$

Major or minor congenital anomalies of the coronary arteries are present in those undergoing cardiac catheterization. Depending upon the origin, course, and termination of the anomalous vessel, certain coronary anomalies may be associated with sudden death, syncope, other congenital heart diseases, or angina syndromes, or they may be incidental findings, without adverse prognosis. Accurate recognition and documentation of coronary artery anomalies at the time of coronary angiography are essential to determine the significance of such findings and to avoid therapeutic complications. ${ }^{[8]}$

Variations in coronary artery anatomy are often recognized in association with structural forms of congenital heart disease. Importantly, coronary artery anomalies are a cause of sudden death in young athletes in the absence of additional heart abnormalities. ${ }^{[9]}$ The coronary artery study in regard to the area of distribution is a matter of prime medical importance. Their physiological significance is indicated by the fact that they utilize $10 \%$ of the blood flowing through the aorta ${ }^{[10]}$ Early and correct diagnosis of anomalies that may compromise the myocardial blood supply is stressed, and possible surgical solutions are offered. Selective coronary angiography is the technique of choice for precise visualization of the coronary artery system. ${ }^{[11]}$

This current study is done to throw light upon the number of coronary ostia, diameter of the trunk, course, branching pattern and termination of right coronary artery and left anterior descending, circumflex artery branches of left coronary artery. This is to help the cardiologists for a better approach to cardiac disease for a precise cure.

\subsection{Right Coronary Artery}

\section{Origin:}

It arises from the anterior aortic sinus (right coronary sinus in clinical usage) of ascending aorta, slightly below the supra-valvar ridge. ${ }^{[12]}$

\section{Course:}

At first the artery passes forwards and to the right between the pulmonary trunk and right auricle; then it passes downwards and to the right along the right part of the atrio-ventricular groove. It winds round the inferior border of the heart, passes upwards and to the left along the posterior part of atrio-ventricular groove and reaches the crux of the heart. In $60 \%$ subjects the terminal part of right coronary artery anastomoses with the circumflex branch of the left coronary artery slightly to the left side of the crux; in $10 \%$ cases the right coronary ends at the inferior border of heart; in $10 \%$ it reaches the interval between the inferior border and the crux of the heart. In the remaining $20 \%$ subjects, right coronary traverses the entire posterior part of the atrioventricular groove. ${ }^{[12]}$

\section{Branches:}

For the purpose of description branches are divided into two groups - those arising from the first segment of the artery (up to the inferior border), and those arising from the second segment (up to the crux). ${ }^{[12]}$

\section{Branches from the first segment}

1.Ventricular rami: Right conus artery,Right anterior ventricular rami (Right marginal artery)

2.Atrial rami: Sinu-atrial nodal artery

Branches from the second segment

1) Right posterior ventricular rami.

2) Posterior interventricular branch (Right descending artery)

Septal rami.

3) Right posterior atrial rami ${ }^{[12]}$ 


\subsection{Left Coronary Artery}

Origin:

It is usually wider than right coronary artery and supplies the large volume of the myocardium. It arises from the left posterior aortic sinus (left coronary sinus in clinical usage) of the ascending aorta ${ }^{[12]}$

\section{Course:}

The trunk of the artery passes behind the pulmonary trunk, and then appears forwards and to the left between the pulmonary trunk and left auricle, where it divides usually into two branches, anterior interventricular and circumflex. On rare occasions $(2 \%)$ the aforesaid branches arise separately from the left posterior aortic sinus. ${ }^{[12]}$

Branches: (1) Anterior ventricular rami (Left descending artery)

(a) Left diagonal artery (b) Left conus artery (c) Septal artery

(2) Circumflex artery

$\begin{array}{ll}\text { (a) Atrial ventricular rami } & \text { (b) Sinu-atrial nodal artery }\end{array}$

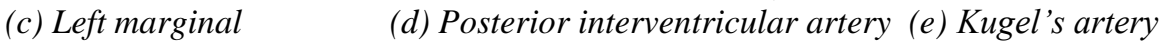

\section{Materials and Methods}

2.1 Material: The material for the present study comprises of adult human heart collected from the cadavers from the dissection hall of anatomy department of S.V.S medical college, Mahabubnagar from 2008 to 2015 telangana state . The hearts of 110 adult south Indian cadavers fixed with $10 \%$ formaldehyde were used. .

\subsection{Instruments used:}

Scalpel : with blade

Forceps: small pointed ,Tooth forceps Non - Toothed forceps

Scissors

Vernier caliper : To measure the diameter of coronary arteries

Scale and Thread : To measure the length of coronary arteries

\subsection{Methods :}

Dissection method

$\mathrm{KOH}$ method

Fevicryl crimson red colour
: To secure the heart specimen.

: To separate the muscle mass.

: To highlight the arterial system.

3.1 Dimensions of coronary artery

\section{Observations}

3.1.1 Diameter: Right coronary artery 2 to $5 \mathrm{~mm}$ only and Left coronary artery from 2 to $6 \mathrm{~mm}$ only.

\begin{tabular}{|c|c|c|c|c|c|c|c|c|}
\hline \multirow{2}{*}{$\begin{array}{l}\text { Specime } \\
\text { n No. }\end{array}$} & \multirow{2}{*}{$\begin{array}{l}\text { Diameter of } \\
\text { RCAMT }\end{array}$} & \multirow[t]{2}{*}{$\begin{array}{l}\text { Diameter } \\
\text { of } \\
\text { LCAMT }\end{array}$} & \multicolumn{2}{|c|}{ Length of RCA } & \multirow{2}{*}{$\begin{array}{l}\text { Length } \\
\text { of PDA }\end{array}$} & \multirow{2}{*}{$\begin{array}{l}\text { Length of } \\
\text { LCMT }\end{array}$} & \multirow{2}{*}{$\begin{array}{l}\text { Length of } \\
\text { LAD }\end{array}$} & \multirow[t]{2}{*}{$\begin{array}{l}\text { Length } \\
\text { of LC }\end{array}$} \\
\hline & & & Segment I & Segment II & & & & \\
\hline 1 & $2 \mathrm{~mm}$ & $3 \mathrm{~mm}$ & $80 \mathrm{~mm}$ & $60 \mathrm{~mm}$ & $40 \mathrm{~mm}$ & $20 \mathrm{~mm}$ & $120 \mathrm{~mm}$ & $80 \mathrm{~mm}$ \\
\hline 2 & $3 \mathrm{~mm}$ & $4 \mathrm{~mm}$ & $75 \mathrm{~mm}$ & $65 \mathrm{~mm}$ & $50 \mathrm{~mm}$ & $23 \mathrm{~mm}$ & $125 \mathrm{~mm}$ & $83 \mathrm{~mm}$ \\
\hline 3 & $2 \mathrm{~mm}$ & $3 \mathrm{~mm}$ & $70 \mathrm{~mm}$ & $60 \mathrm{~mm}$ & $40 \mathrm{~mm}$ & $22 \mathrm{~mm}$ & $110 \mathrm{~mm}$ & $78 \mathrm{~mm}$ \\
\hline 4 & $5 \mathrm{~mm}$ & $6 \mathrm{~mm}$ & $70 \mathrm{~mm}$ & $50 \mathrm{~mm}$ & $50 \mathrm{~mm}$ & $20 \mathrm{~mm}$ & $127 \mathrm{~mm}$ & $75 \mathrm{~mm}$ \\
\hline 5 & $3 \mathrm{~mm}$ & $4 \mathrm{~mm}$ & $60 \mathrm{~mm}$ & $30 \mathrm{~mm}$ & $35 \mathrm{~mm}$ & $25 \mathrm{~mm}$ & $140 \mathrm{~mm}$ & $85 \mathrm{~mm}$ \\
\hline 6 & $4 \mathrm{~mm}$ & $5 \mathrm{~mm}$ & $50 \mathrm{~mm}$ & $30 \mathrm{~mm}$ & $40 \mathrm{~mm}$ & $25 \mathrm{~mm}$ & $145 \mathrm{~mm}$ & $90 \mathrm{~mm}$ \\
\hline 7 & $2 \mathrm{~mm}$ & $3 \mathrm{~mm}$ & $40 \mathrm{~mm}$ & $30 \mathrm{~mm}$ & $35 \mathrm{~mm}$ & $23 \mathrm{~mm}$ & $140 \mathrm{~mm}$ & $80 \mathrm{~mm}$ \\
\hline 8 & $3 \mathrm{~mm}$ & $2 \mathrm{~mm}$ & $50 \mathrm{~mm}$ & $40 \mathrm{~mm}$ & $40 \mathrm{~mm}$ & $22 \mathrm{~mm}$ & $120 \mathrm{~mm}$ & $60 \mathrm{~mm}$ \\
\hline 9 & $3 \mathrm{~mm}$ & $4 \mathrm{~mm}$ & $75 \mathrm{~mm}$ & $35 \mathrm{~mm}$ & $40 \mathrm{~mm}$ & $15 \mathrm{~mm}$ & $140 \mathrm{~mm}$ & $65 \mathrm{~mm}$ \\
\hline 10 & $4 \mathrm{~mm}$ & $5 \mathrm{~mm}$ & $80 \mathrm{~mm}$ & $40 \mathrm{~mm}$ & $30 \mathrm{~mm}$ & $18 \mathrm{~mm}$ & $135 \mathrm{~mm}$ & $60 \mathrm{~mm}$ \\
\hline 11 & $2 \mathrm{~mm}$ & $2 \mathrm{~mm}$ & $60 \mathrm{~mm}$ & $30 \mathrm{~mm}$ & $40 \mathrm{~mm}$ & $20 \mathrm{~mm}$ & $125 \mathrm{~mm}$ & $65 \mathrm{~mm}$ \\
\hline 12 & $5 \mathrm{~mm}$ & $4 \mathrm{~mm}$ & $50 \mathrm{~mm}$ & $20 \mathrm{~mm}$ & $45 \mathrm{~mm}$ & $22 \mathrm{~mm}$ & $145 \mathrm{~mm}$ & $70 \mathrm{~mm}$ \\
\hline 13 & $4 \mathrm{~mm}$ & $6 \mathrm{~mm}$ & $60 \mathrm{~mm}$ & $40 \mathrm{~mm}$ & $40 \mathrm{~mm}$ & $19 \mathrm{~mm}$ & $145 \mathrm{~mm}$ & $85 \mathrm{~mm}$ \\
\hline 14 & $3 \mathrm{~mm}$ & $5 \mathrm{~mm}$ & $50 \mathrm{~mm}$ & $40 \mathrm{~mm}$ & $35 \mathrm{~mm}$ & $20 \mathrm{~mm}$ & $140 \mathrm{~mm}$ & $75 \mathrm{~mm}$ \\
\hline 15 & $4 \mathrm{~mm}$ & $5 \mathrm{~mm}$ & $60 \mathrm{~mm}$ & $30 \mathrm{~mm}$ & $30 \mathrm{~mm}$ & $15 \mathrm{~mm}$ & $120 \mathrm{~mm}$ & $60 \mathrm{~mm}$ \\
\hline 16 & $3 \mathrm{~mm}$ & $5 \mathrm{~mm}$ & $50 \mathrm{~mm}$ & $40 \mathrm{~mm}$ & $35 \mathrm{~mm}$ & $15 \mathrm{~mm}$ & $145 \mathrm{~mm}$ & $75 \mathrm{~mm}$ \\
\hline 17 & $2 \mathrm{~mm}$ & $4 \mathrm{~mm}$ & $70 \mathrm{~mm}$ & $50 \mathrm{~mm}$ & $40 \mathrm{~mm}$ & $18 \mathrm{~mm}$ & $135 \mathrm{~mm}$ & $65 \mathrm{~mm}$ \\
\hline
\end{tabular}


Anatomical Variations In Branching Pattern And Dimensions Of Coronary Arteries: A Cadaveric ..

\begin{tabular}{|l|l|l|l|l|l|l|l|l|}
$\mathbf{1 8}$ & $\mathbf{5 m m}$ & $\mathbf{5 m m}$ & $60 \mathrm{~mm}$ & $30 \mathrm{~mm}$ & $45 \mathrm{~mm}$ & $19 \mathrm{~mm}$ & $140 \mathrm{~mm}$ & $55 \mathrm{~mm}$ \\
\hline $\mathbf{1 9}$ & $4 \mathrm{~mm}$ & $6 \mathrm{~mm}$ & $80 \mathrm{~mm}$ & $40 \mathrm{~mm}$ & $50 \mathrm{~mm}$ & $20 \mathrm{~mm}$ & $140 \mathrm{~mm}$ & $60 \mathrm{~mm}$ \\
\hline $\mathbf{2 0}$ & $3 \mathrm{~mm}$ & $4 \mathrm{~mm}$ & $80 \mathrm{~mm}$ & $30 \mathrm{~mm}$ & $40 \mathrm{~mm}$ & $22 \mathrm{~mm}$ & $145 \mathrm{~mm}$ & $65 \mathrm{~mm}$ \\
\hline $\mathbf{2 1}$ & $3 \mathrm{~mm}$ & $4 \mathrm{~mm}$ & $90 \mathrm{~mm}$ & $30 \mathrm{~mm}$ & $30 \mathrm{~mm}$ & $16 \mathrm{~mm}$ & $145 \mathrm{~mm}$ & $60 \mathrm{~mm}$ \\
\hline $\mathbf{2 2}$ & $3 \mathrm{~mm}$ & $4 \mathrm{~mm}$ & $70 \mathrm{~mm}$ & $30 \mathrm{~mm}$ & $40 \mathrm{~mm}$ & $19 \mathrm{~mm}$ & $140 \mathrm{~mm}$ & $75 \mathrm{~mm}$ \\
\hline
\end{tabular}

\begin{tabular}{|l|l|l|}
\hline Artery & No. of specimens & Percentage \\
\hline LCA > RCA & 90 & $82 \%$ \\
\hline LCA < RCA & 10 & $9 \%$ \\
\hline LCA = RCA & 10 & $9 \%$ \\
\hline
\end{tabular}

Table No 1: Diameter Of The Main Trunk (\%)

DIAMETER OF MAIN TRUNK (\%)

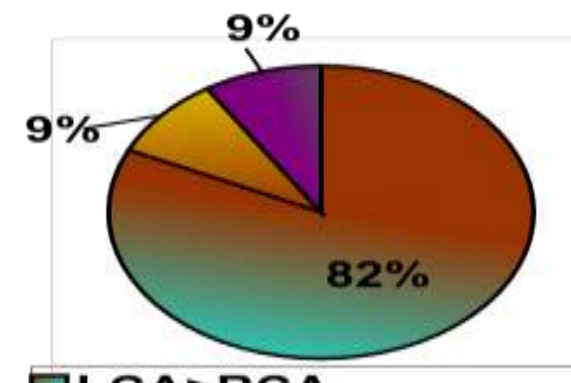

$\square$ LCA $>$ RCA

口LCA $A R C A$

Table No 2: Diameter Of Main Trunk In Mm

\begin{tabular}{|l|l|l|}
\hline Measurement in "mm" & RCA & LCA \\
\hline $\mathbf{2 m m}$ & 13 & 5 \\
\hline $\mathbf{3 m m}$ & 22 & 8 \\
\hline $\mathbf{4 m m}$ & 13 & 20 \\
\hline $\mathbf{5 m m}$ & 7 & 15 \\
\hline $\mathbf{6 m m}$ & - & 7 \\
\hline
\end{tabular}

3.1.2 Length Of Coronary Arteries Ranges

Table No 3 Showing Data Of : Length Of Coronary Arteries Ranges Mm

\begin{tabular}{|l|l|}
\hline Artery & Ranges of length \\
\hline RCA & 100 to $130 \mathrm{~mm}$ \\
\hline PDA & 30 to $50 \mathrm{~mm}$ \\
\hline LCMT & 15 to $25 \mathrm{~mm}$ \\
\hline LAD & 120 to $145 \mathrm{~mm}$ \\
\hline LC & 60 to $80 \mathrm{~mm}$ \\
\hline
\end{tabular}

\subsection{Branching Pattern}

3.2.1 Variations Of RCA

Table No 4: Data Of Variations Of RCA

\begin{tabular}{|l|l|}
\hline ARTERY & \% OF VARIATIONS \\
\hline $\begin{array}{l}\text { Right aortic sinus } \\
\text { continues as a RCA in }\end{array}$ & $70 \%$ \\
\hline $\begin{array}{l}\text { Right aortic sinus } \\
\text { bifurcated as RCA \& } \\
\text { Conus artery }\end{array}$ & $30 \%$ \\
\hline ARTERY & \% OF VARIATIONS \\
\hline $\begin{array}{l}\text { single PDA arises from } \\
\text { RCA }\end{array}$ & $80 \%$ \\
\hline $\begin{array}{l}\text { or } 3 \text { PDA arises from } \\
\text { RCA }\end{array}$ & $20 \%$ \\
\hline
\end{tabular}




3.2.3 VARIATIONS OF LCA
TABLE NO 6: SHOWING DATA OF VARIATIONS OF LCA
\begin{tabular}{|c|c|}
\hline ARTERY & \% OF VARIATIONS \\
\hline LCA bifurcated & $86 \%$ \\
\hline trifurcated & $14 \%$ \\
\hline
\end{tabular}

\section{Discussion}

The branching pattern and distribution of coronary arteries have been studied by various workers in the past. Coronary artery disease is one of the most common causes of death due to changing dietary habits, sedentary habits, smoking etc, in developing countries like India. With the advancement of medical technology, the incidence of coronary angiography and coronary bypass surgeries, stunt, balloon angioplasty is also increasing. The present study was taken up with the hope that the data collected in the study may help clinician to interpret properly the findings which will lead on to its remedy.

In this study, a note on the origin of coronary arteries, diameter of the main trunk, length of the main trunks of RCA and LCA, length of the RCA 1 and 2 segments, length of PDA, length of LAD and LCX arteries, was done

\subsection{Anomalous Origin Of Coronary Arteries}

Heart receives its arterial supply from right and left coronary arteries. The right coronary artery arises from anterior aortic sinus. Sometimes this sinus has two ostia. SCHLERINGER et al named the second artery as conus artery referred as $3^{\text {rd }}$ coronary artery is correlated by present study (specimen No 19) in which conus artery was aroused directly from right anterior aortic sinus and supply the infundibulam of right ventricle.

Cheathan J.P Et Al (1987) Reported Origin Of Right Coronary Artery From Descending Thoracic Aorta. Nakano. M et al (1993), VOGT PR et al (1994) reported anomalous origin of right coronary artery from pulmonary artery. DURAN A.C et al (1994) and SANUDO. J.R. et al (1998) reported origin of right coronary artery from left posterior aortic sinus. $\quad$ BORDES. P and MAINAR. V (1994) observed origin of right coronary artery from left anterior descending artery from main trunk of left coronary artery and from circumflex artery in three cases, only single coronary artery was present. In the present study no abnormal origin of right coronary artery was observed.

The left coronary artery commonly arises from left posterior aortic sinus. JAMES (1961) studied 106 hearts and in all the hearts, left coronary artery arose from left posterior aortic sinus from a single ostium. LOPEZ Candal J et al (1995), SAFI AM et al (2001) reported anomalous origin of left coronary from right sinus. Pfannschmidt J et al (1992) and CABRERA et al (1999), reported anomalous origin of left coronary artery from pulmonary trunk. In the present study, the left coronary artery arose from left posterior aortic sinus it's correlating with the study of JAMES (1961)

\subsection{Diameter Of Coronary Arteries}

In the present study the diameter of the main trunk revealed that in majority of hearts i.e., in $82 \%$ the diameter of left coronary artery was more than that of right coronary artery, in $9 \%$ of the hearts the diameter of right coronary artery was more than left and in remaining $9 \%$ both right and left coronary artery diameters were equal. The average diameter of the RCA was 2 to $4 \mathrm{~mm}$. In LCA the initial section is dilated, elsewhere it has a diameter of 2 to $6 \mathrm{~mm}$. The present study correlating with PAULIN(1964) already reported the diameter ranges of RCA from 1.5 to $5.5 \mathrm{~mm}$ and LCA 2 to $7 \mathrm{~mm}$

Macalpin et al, 1973; Robert and Robert 1980; Dedge et al 1992 Study conducted in 50 hearts revealed the diameter of left coronary was $8.1 \mathrm{~mm}$ and right coronary artery near origin was $6.1 \mathrm{~mm}$. Is approximately correlating with the present study.

\subsection{Length Of Coronary Arteries}

In present study coronary arteries length ranges: RCA: 100 to $130 \mathrm{~mm}$, PDA: 30 to $50 \mathrm{~mm}$, LCMT: 15 to $25 \mathrm{~mm}$, LAD: 120 to $145 \mathrm{~mm}$, LC: 60 to $80 \mathrm{~mm}$. is correlating with Waller,B.F, MD. Schlant reported The left main (LM) coronary artery ranges in length from 1 to $25 \mathrm{~mm}$ before bifurcating into the left anterior descending (LAD) and left circumflex (LC) branches. The LAD coronary artery measures from 10 to $13 \mathrm{~cm}$ in length, whereas the usual non-dominant LC artery measures about 6 to $8 \mathrm{~cm}$ in length. The dominant right coronary artery (RCA) is about 12 to $14 \mathrm{~cm}$ in length, before giving rise to the posterior descending artery (PDA). And approximately correlated with Cristian Lorenz, Jens Von Berg et al (2004) Reported Left Dominance: LAD: 168mm, LCX: 99mm, RCA: 103mm, Right Dominance: LAD:168mm, LCX: 77mm, RCA:215mm 


\section{Conclusion}

The present study on branching pattern and distribution of coronary arteries shows some difference with respect to the results from the available literature. Diameter of right coronary artery ranges from 2 to $5 \mathrm{~mm}$ only and left coronary artery from 2 to $6 \mathrm{~mm}$ only. Length of coronary arteries ranges: RCA: 100 to $130 \mathrm{~mm}$, PDA: 30 to $50 \mathrm{~mm}$, LCMT: 15 to $25 \mathrm{~mm}$, LAD: 120 to $145 \mathrm{~mm}$, LC: 60 to $80 \mathrm{~mm}$ Better anatomical knowledge about the branches of coronary artery and its variation is essential for cardiologists and interpretation of coronary angiograms by radiologist. Work done in the present study was just like exploring the tip of iceberg. The rest of it needs have been explored.
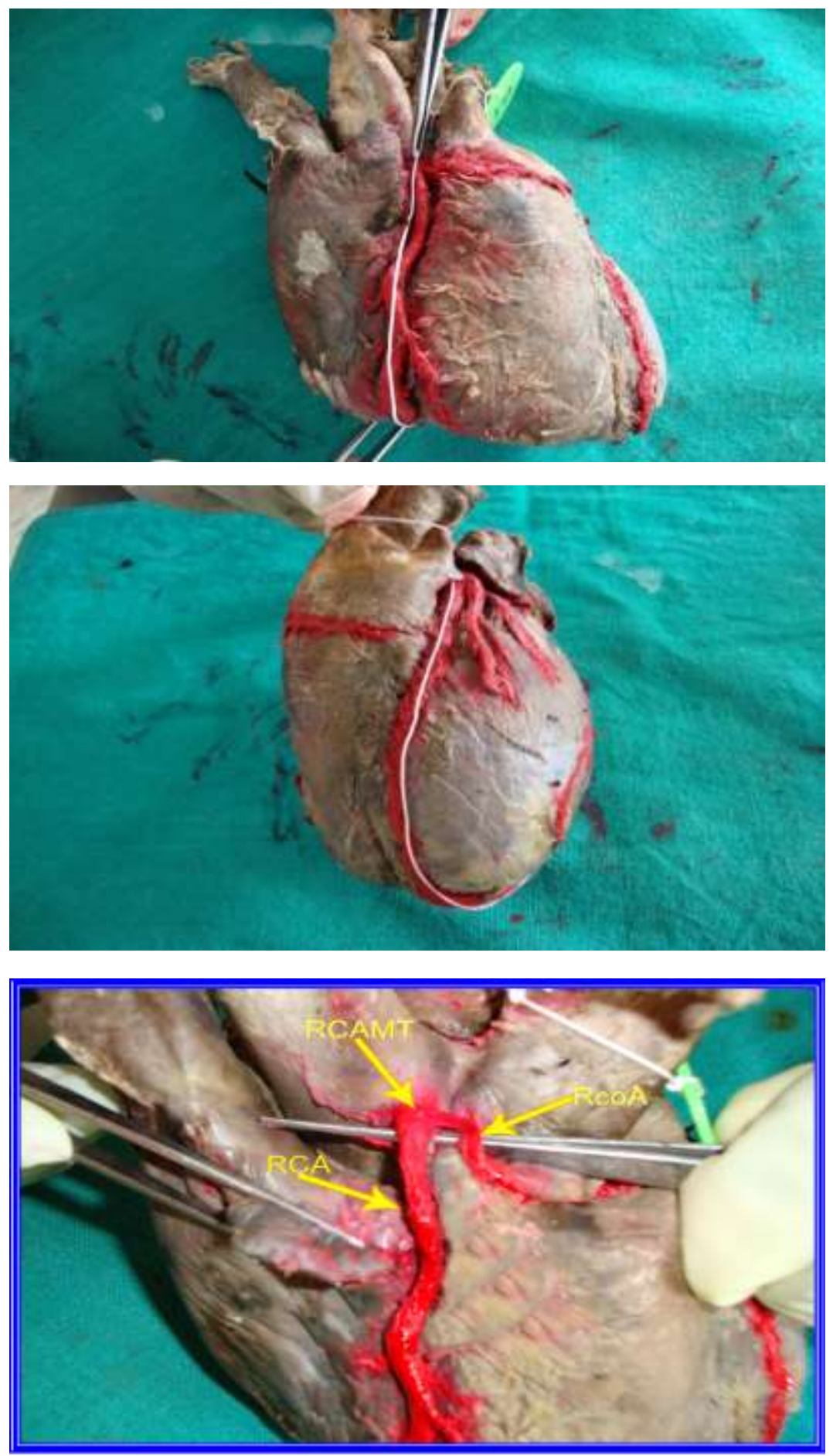

Specimen No. 19 showing RCAMT dividing into RCA and RcoA ( it is referred as $3^{\text {rd }}$ Coronary Artery) 

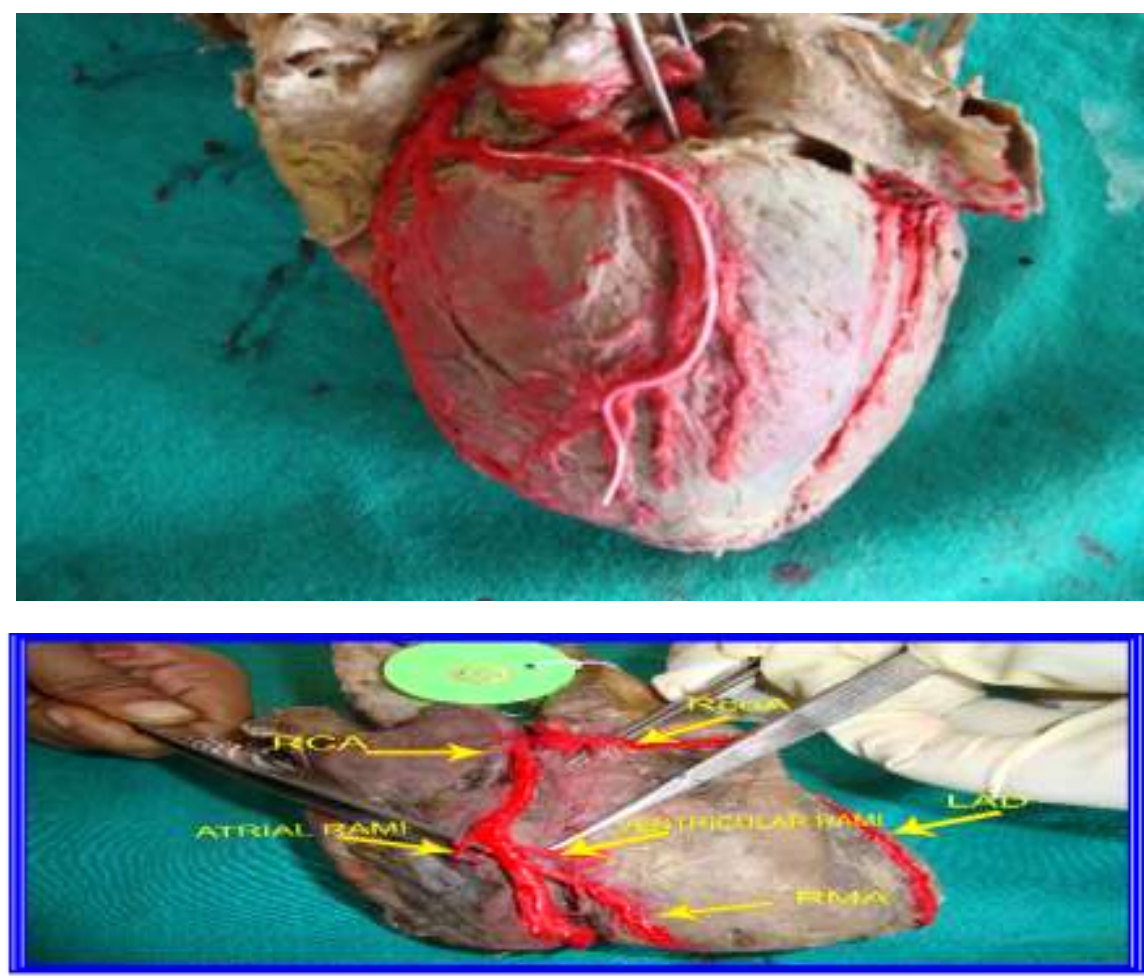

Specimen No. 9 showing normal Coronarv Arteries in Anterior viem

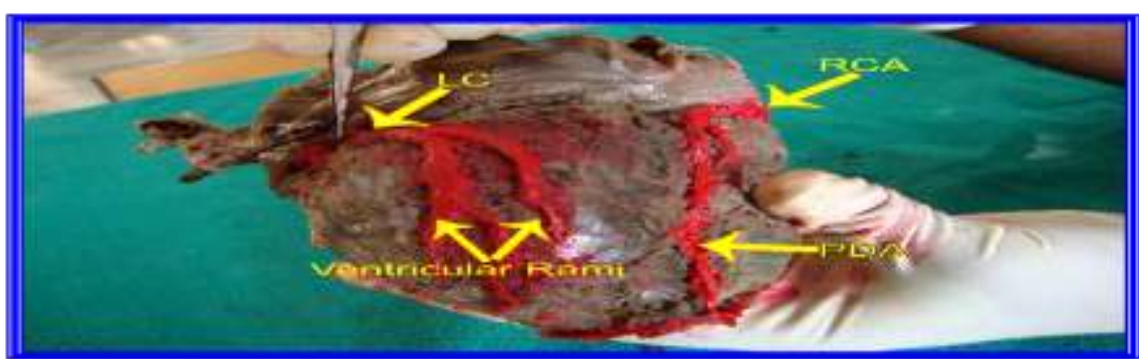

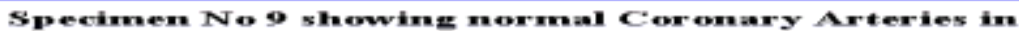
Pasterier viev
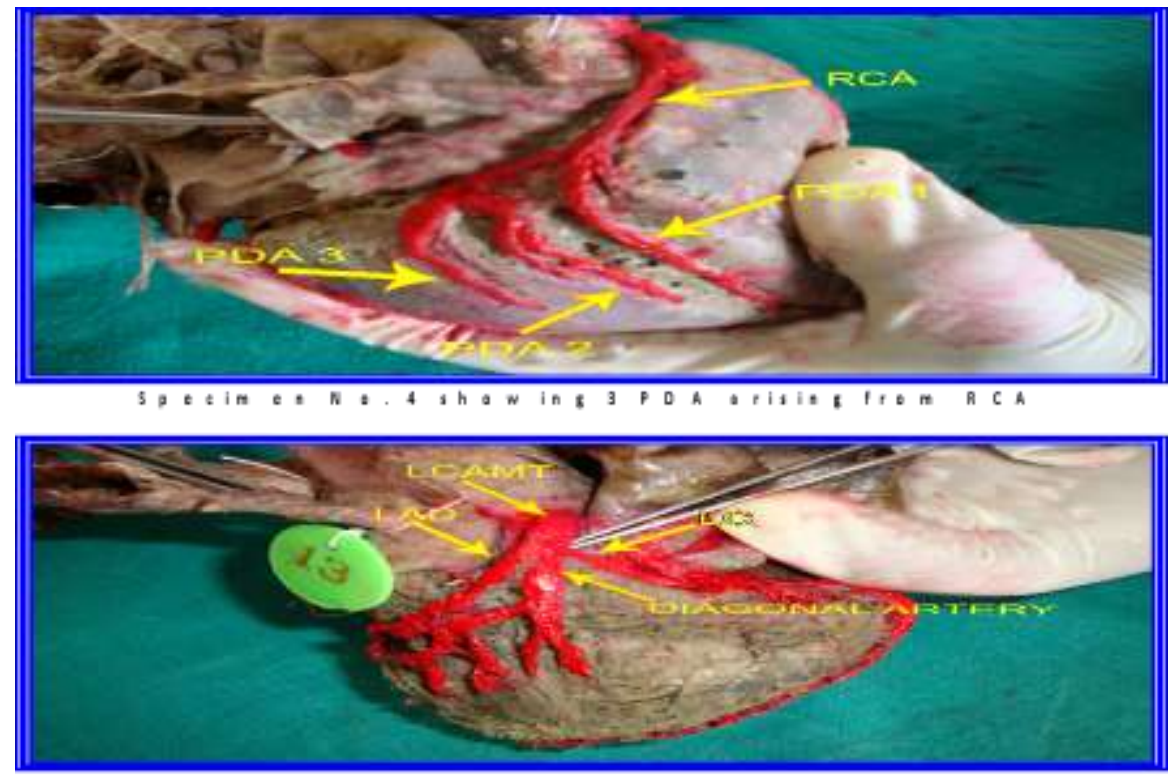

Specimem No.13 showimg ICANTT Trirnxeration 


\section{References}

[1]. Co-ro-ne. Dorland's illustrated medical dictionary. 30th edt, Philadelphia:Saunders, 2000:420.

[2]. Allwork SP. The applied anatomy of the arterial blood supply to the heart in man. Anat Soci Great Britian and Ireland Aug 1987;153:1-16.

[3]. Data AK. Essentials of human anatomy. Thorax and abdomen. 3rd Ed., Calcutta, Current Books International. 1994; 80-86

[4]. Frescura C, Basso C, Thiene G, Corrado D, Pennelli T, Angelini A, Daliento L. Anomalous origin of coronary arteries and risk of sudden death: a study based on an autopsy population of congenital heart disease. Hum. Pathol. 1998; 29: 689-695.

[5]. Vikram Palimar "Origin of right coronary artery from the left sinus of Valsalva" International Journal of Anatomical Variations 2008; 1: 12-13

[6]. Walmsley R, Watson H, Kirklin JW. Clinical anatomy of the heart. Edinburgh: Churchill Livingstone; 1978:199-214.

[7]. Kalpana R. A study of principal branches of coronary arteries in human. J Anat Soc. India Dec 2003;52:2:137-140.

[8]. Charles E. Wilkins et al "Coronary Artery Anomalies" A Review of More than 10,000 Patients from The Clayton Cardiovascular Laboratories" Texas Heart Institute Journal 1988;15:166-173

[9]. Pelech AN. Coronary artery anamolies. www.imedicine.com (as accessed on Sep. 5th, 06) e Med Specialties Cardiol : Web MD, 2006.

[10]. Luzsa G. X-ray anatomy of the vascular system. London : Butterworths and co-publishers Ltd; 1974:30-33.

[11]. M. Trivellato, M.D., Paolo Angelini, M.D., and Robert D. Leachman, M.D. "Variations in coronary artery anatomy: Normal versus Abnormal" Cardiovascular Diseases, Bulletin of the Texas Heart Institute Volume 7 Number 4 December 1980; 357-370.

[12]. A.K .Datta $7^{\text {th }}$ edition "Essentials Of Human Anatomy Thorax And Abdomen" page 68-72 